\title{
PENGARUH SUHU DAN LAMA PENYIMPANAN TERHADAP STABILITAS WARNA SARI BUAH NAGA MERAH (Hylocereus polyrhizus Brriton and Rose)
}

\author{
Eka Widiya Wati, ${ }^{1, *}$, Nur Mita ${ }^{1,2}$, Mirhansyah Ardana ${ }^{1,2}$ \\ ${ }^{1}$ Laboratorium Penelitian dan Pengembangan Kefarmasian "Farmaka Tropis", \\ Fakultas Farmasi, Universitas Mulawarman, Samarinda, Indonesia \\ ${ }^{2}$ Kelompok KeilmuanTeknologi Farmasi, Fakultas Farmasi, Universitas Mulawarman, \\ Samarinda, Indonesia \\ *Email: ekawidiyawati17@gmail.com
}

\begin{abstract}
The Research of the effect of temperature and storage time on the stability of dragon fruit juice has been conducted. The aim of this study is to identify secondary metabolites of red dragon fruit juice and to know the stability of the pigments color of dragon fruit on the effect of $\mathrm{pH}$ and storage temperature. Identification of secondary metabolites of dragon fruit juice was carried out by using alkaloids, flavonoids, anthocyanins, steroids, tannins and saponins reagents. Stability of dragon fruit juice pigments color was measured in various temperatures cold temperature $\left(14^{\circ} \mathrm{C}\right)$ and room temperature $\left(30^{\circ} \mathrm{C}\right)$ and storage times (the $0^{\text {th }}, 1^{\text {st }}, 2^{\text {nd }}, 4^{\text {th }}, 5^{\text {th }}, 6^{\text {th }}$, and $7^{\text {th }}$ days) by measuring the absorbance of red dragon fruit using $U V$-Vis spectrophotometer at anthocyanin wavelength $(534 \mathrm{~nm})$. The results showed that dragon fruit juice contained alkaloids, flavonoids, anthocyanins, and saponins, and the measurement results showed red dragon fruit juice pigments color was more stable at cold temperatures $\left(14^{\circ} \mathrm{C}\right)$ compared to room temperature $\left(30^{\circ} \mathrm{C}\right)$.
\end{abstract}

Keywords: anthocyanin, temperature, red dragon fruit

\begin{abstract}
ABSTRAK
Telah dilakukan penelitian tentang pengaruh suhu dan lama penyimpanan terhadap stabilitas sari buah naga.Penelitian ini bertujuan untuk mengidentifikasi metabolit sekunder sari buah naga merah dan mengetahui stabilitas pigmen warna dari sari buah naga terhadap pengaruh suhu dan lama penyimpanan. Identifikasi metabolit sekunder sari buah naga dilakukan dengan menguji alkaloid, flavonoid, antosianin, steroid, tanin dan saponin, pengukuran suhu dan lama penyimpanan dilakukan dengan mengukur absorbansi sari buah naga merah dengan menggunakan spektrofotometer $u v$-vis pada panjang gelombang antosianin $(534 \mathrm{~nm})$ pada variasi suhu dingin $\left(14^{\circ} \mathrm{C}\right)$ dan suhu ruang $\left(30^{\circ} \mathrm{C}\right)$ pada durasi waktu hari ke-0, 1, 2, 4, 5,6, dan 7 hari. Hasil penelitian diperoleh sari buah naga mengandung alkaloid, flavonoid, antosianin, dan saponin, dan hasil pengukuran menunjukkan stabilitas warna sari buah naga merah lebih baik pada suhu dingin $\left(14^{\circ} \mathrm{C}\right)$ dibandingkan dengan suhu ruang $\left(30^{\circ} \mathrm{C}\right)$.
\end{abstract}

Kata kunci: antosianin, suhu,buah naga merah 
DOI: https://doi.org/10.25026/mpc.v8i1.299

\section{PENDAHULUAN}

Buah naga merah (H. polyrhizus) merupakan tanaman buah naga yang memiliki kulit merah dan daging buah berwarna merah keunguan. Buah naga memiliki beberapa manfaat dibidang kesehatan seperti sebagai obat diabetes mellitus, pencegah kanker usus, mengurangi kadar kolesterol [1]. Selain itu zat warna yang terkandung di dalam buah naga dapat dimanfaatkan sebagai bahan pewarna alami karena mengandung senyawa antosianin yang merupakan zat warna yang berperan memberikan warna merah sampai biru sehingga dapat dijadikan alternatif pewarna sintetik.

Zat pewarna alami yang berpotensi untuk diekstrak adalah antosianin. Antosianin merupakan kelompok pigmen yang memiliki warna dari merah sampai biru yang terdapat pada tanaman[2]. Antosianin termasuk kedalam golongan flavonoid yang bersifat polar dan dapat diekstraksi dengan pelarut polar[3].

Stabilitas suatu pigmen warna antosianin dipengaruhi beberapa faktor intrinsik dan ekstrinsik dalam produk, seperti $\mathrm{pH}$, suhu penyimpanan, struktur kimia dan konsentrasi yang ada, keberadaan cahaya, oksigen, enzim dan ion logam[4]. Dari beberapa faktor stabilitas antosianin tersebut maka dilakukanlah penelitian uji stabilitas zat warna buah naga merah.

Penelitian ini dilakukan dengan menggunakan daging buah naga merah dan menentukan stabilitas pigmen warna terhadap pengaruh suhu dan lama penyimpanan.

\section{METODE PENELITIAN}

\begin{abstract}
Alat dan Bahan
Peralatan yang digunakan dalam penelitian ini adalah kulkas, kuvet, spatel logam, seperangkat alat gelas, hot plate, timbangan analitik, thermometer dan vortex.

Bahan yang digunakan pada penelitian ini adalah sari buah naga merah, aquades, asam asetat anhidrat, $\mathrm{Bi}\left(\mathrm{NO}_{3}\right)_{3}, \mathrm{FeCl}_{3} 1 \%, \mathrm{H}_{2} \mathrm{SO}_{4}, \mathrm{HNO}_{3}$, $\mathrm{HCl}, \mathrm{HgCl}_{2}, \mathrm{I}_{2}, \mathrm{KI}, \mathrm{NaOH}$, kloroform.
\end{abstract}

\section{Pengumpulam bahan tumbuhan}

Dikumpulkan sampel buah naga merah yang diperoleh dari kebun buah naga di wilayah jalan poros Samarinda, Kalimantan timur. Dipisahkan kulit buah naga dan daging buah naga, kemudian ditimbang berat daging buah naga yang diperoleh.

\section{Ekstraksi}

Ditimbang daging buah naga sebanyak, kemudian di dimasukkan kedalam alat juicer, ditampung hasil sari buah naga yang didapatkan kemudian disaring menggunakan kertas saring. Ditimbang hasil sari buah naga yang telah disaring.

\section{Identifikasi Metabolit Sekunder}

Uji fitokimia dilakukan untuk mengetahui jenis metabolit sekunder yang terkandung pada sari buah naga (Hylocereus polyrhizus).

\section{Uji Alkaloid}

Diambil 3 tabung reaksi masingmasing dimasukkan $2 \mathrm{~mL}$ sari buah naga lalu ditambahkan masing-masing tabung reaksi dengan 3 tetes pereaksi wagner, pereaksi mayer, dan pereaksi dragendorff. 


\section{Uji Flavonoid}

Diambil $2 \mathrm{~mL}$ sari buah naga dimasukan dalam tabung reaksi lalu ditambahkan 0,2 gram serbuk $\mathrm{Mg}$ dan 5 $\mathrm{mL} \mathrm{HCl}$ pekat.

\section{Uji Antosianin}

Diambil $2 \mathrm{~mL}$ sari buah naga dimasukan dalam tabung reaksi lalu ditambahkan $2 \mathrm{~mL} \mathrm{HCl} 2 \mathrm{M}$ dipanaskan pada suhu $100^{\circ} \mathrm{C}$ selama 5 menit dan juga ditambahkan $\mathrm{NaOH} 2 \mathrm{M}$ tetes demi tetes sambil diamati perubahan yang terjadi.

\section{Uji Tanin}

Diambil $2 \mathrm{~mL}$ sari buah naga dimasukan dalam tabung reaksi lalu ditambahkan $\mathrm{FeCl}$ 1\% sebanyak $5 \mathrm{~mL}$.

\section{Uji Steroid}

Diambil $2 \mathrm{~mL}$ sari buah naga dimasukan dalam tabung reaksi lalu ditambahkan $2 \mathrm{~mL}$ kloroform, 2 tetes asam asetat glasial, dan 2 tetes $\mathrm{H}_{2} \mathrm{SO}_{4}$.

\section{Uji Saponin}

Diambil $2 \mathrm{~mL}$ sari buah naga dimasukan dalam tabung reaksi lalu ditambahkan $10 \mathrm{~mL}$ air panas kemudian dikocok selama 1 menit.

\section{Uji Stabilitas Warna Sari Buah Naga terhadap Suhu dan Lama Penyimpanan.}

Sari buah naga disimpan dalam 2 kondisi penyimpanan yaitu, suhu dingin $\left(14^{\circ} \mathrm{C}\right)$ dan suhu ruang $\left(30^{\circ} \mathrm{C}\right)$ selama 1 minggu, kemudian sari buah naga merah dibuat 4 seri konsentrasi (1:40, 1:60, 1:80, dan 1:100) dengan menggunakan pelarut etanol p.a dandiukur absorbansi menggunakan spektrofotometer uv-vis pada panjang gelombang $534 \mathrm{~nm}$.

\section{HASIL DAN PEMBAHASAN}

\section{Ekstraksi}

Proses ekstraksi buah naga dilakukan dengan alat juicer. Penggunaan alat juicer dilakukan untuk memperoleh sari dari buah naga sehingga yang digunakan dalam penelitian adalah sari buah naga. Dari proses ekstrasi sari buah naga diperoleh rendemen sebesar $44,43 \%$.

\section{Uji Fitokimia}

Berdasarkan hasil identifikasi metabolit sekunder yang telah dilakukan terhadap sari buah naga merah, diketahui jenis metabolit sekunder yang terdapat pada sari buah naga merah pada tabel 1.

Tabel 1 Hasil uji fitokimia dari sari buah naga

\begin{tabular}{c|c}
\hline Jenis Senyawa & Hasil \\
\hline Alkaloid & + \\
Flavonoid & + \\
Antosianin & + \\
Steroid & - \\
Tanin & - \\
Saponin & + \\
\hline Keterangan : \\
$+\quad=$ Mengandung \\
senyawa metabolit \\
$-\quad=$ Tidak Mengandung senyawa metabolit \\
sekunder
\end{tabular}

Hasil tersebut menunjukkan bahwa pada sari buah naga merah mengandung alkaloid yang ditunjukan dengan adanya endapan berwarna saat diberikan pereaksi, flavonoid ditunjukkan dengan perubahan warna menjadi merah, antosianin ditunjukkan dengan warna merah tidak hilang saat pemberian $\mathrm{HCl}$ dan saat pemberian $\mathrm{NaOH}$ timbul warna hijau yang memudar perlahan, dan saponin ditunjukkan dengan timbulnya busa stabil. Hasil yang telah didapatkan, diperoleh dari pengamatan saat larutan uji diberikan pereaksi seperti adanya perubahan warna, terdapat endapan yang berwarna dan timbulnya busa. 


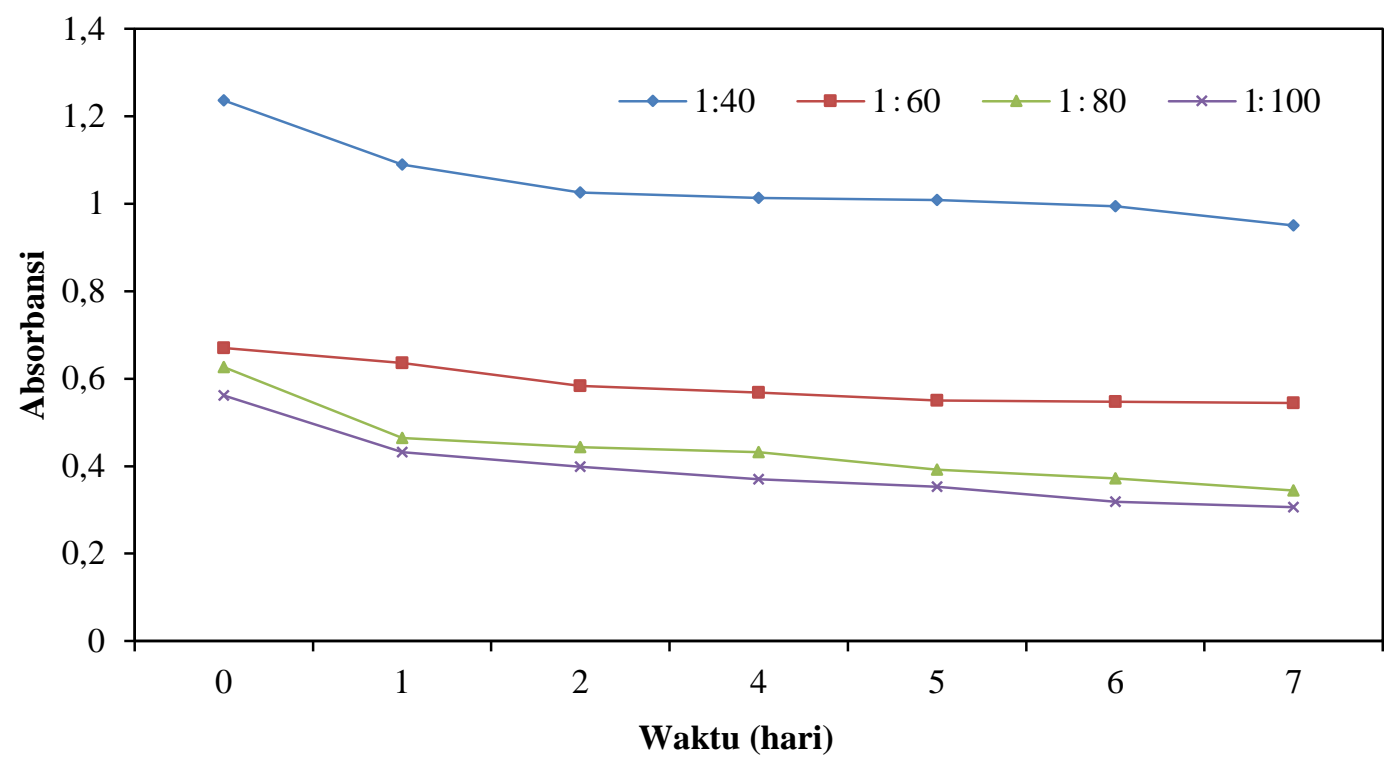

Gambar 1. Grafik hubungan absorbansi dengan waktu penyimpanan pada suhu dingin $\left(14^{\circ} \mathrm{C}\right)$

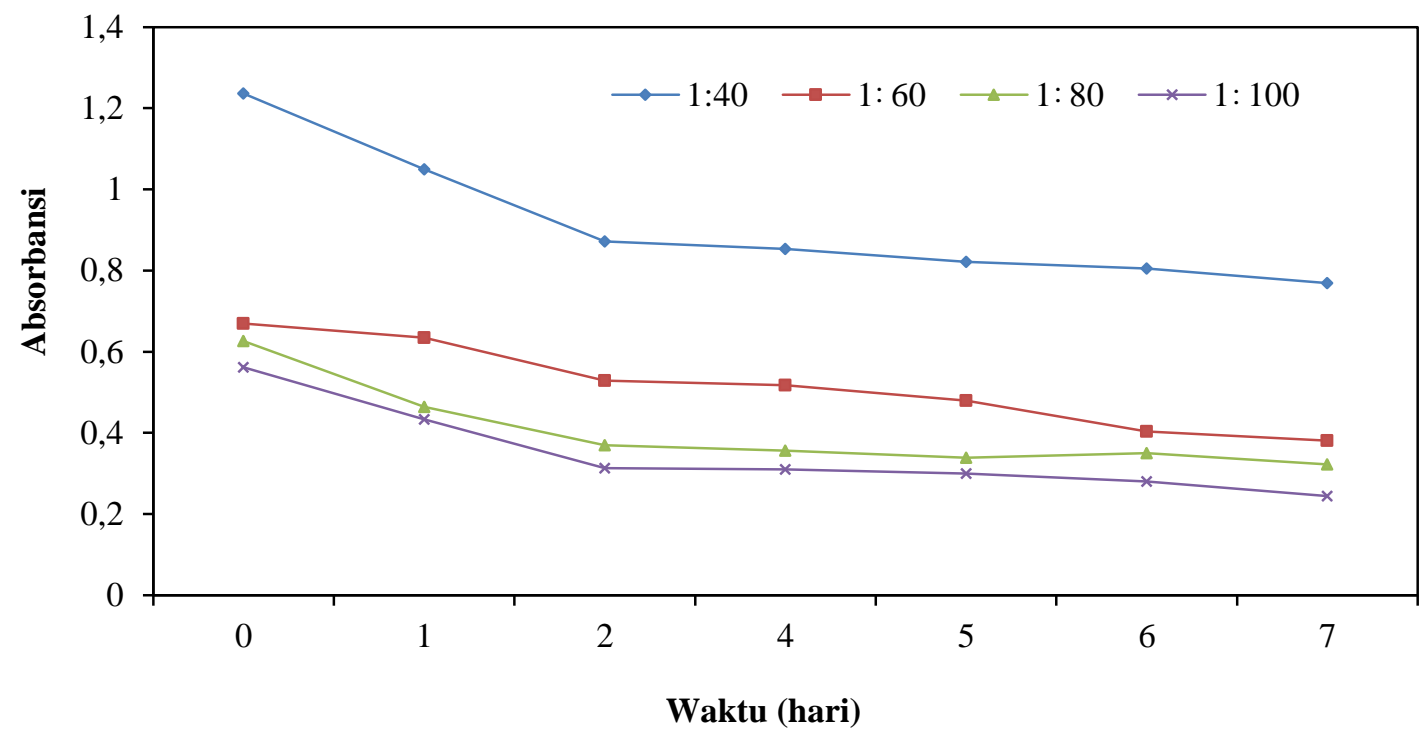

Gambar 2. Grafik hubungan absorbansi dengan waktu penyimpanan pada suhu ruang $\left(30^{\circ} \mathrm{C}\right)$

\section{Uji Stabilitas Pengaruh Suhu Penyimpanan}

Hasil uji stabilitas pigmen warna terhadap pengaruh suhu dan lama penyimpanan menunjukkan bahwa absorbansi mengalami penurunan dari hari ke-0 sampai hari ke-7. Sebagaimana tampak pada gambar 1 dan 2.
Stabilitas warna antosianin dari sari buah naga terhadap suhu penyimpanan menunjukan pada penurunan absorbansi pada suhu dingin $\left(14^{\circ} \mathrm{C}\right)$ lebih rendah dibandingkan suhu ruang $\left(30^{\circ} \mathrm{C}\right)$. Suhu memiliki peranan penting terhadap kestabilan antosianin, suhu penyimpanan maupun suhu proses 
pengolahan mempengaruhi degradasi antosianin [5].

Suhu penyimpanan yang rendah dapat menginaktifkan enzim, sehingga dapat menjaga stabilitas dan memperlambat degradasi antosianin [6]. Peningkatan suhu dapat menyebabkan warna memudar dan terjadinya dekomposisi antosianin dari bentuk aglikon menjadi kalkon tidak berwarna [7].

\section{KESIMPULAN}

Berdasarkan penelitian yang telah dilakukan maka dapat disimpulkan bahwa sari buah naga merah memiliki kandungan alkaloid, flavonoid, antosianin dan saponin. Zat warna sari buah naga merah lebih stabil disimpan pada suhu dingin $\left(14^{\circ} \mathrm{C}\right)$ dibandingkan pada suhu ruang $\left(30^{\circ} \mathrm{C}\right)$.

\section{DAFTAR PUSTAKA}

[1] Kristanto, D. 2009. Buah Naga Pembudidayaan di Pot dan di Kebun. Penebar Swadaya. Jakarta.

[2] Harborne, J.B. 1989. Metode Fitokimia Penuntun Cara Modern Menganalisa Tumbuhan. ITB. Bandung.
[3] Moulana, R. 2012. Efektivitas Penggunaan Jenis Pelarut dan Asam dalam Proses Ekstraksi Pigmen Antosianin Kelopak Bungan Rosella. Jurnal Forum Teknik,Uni versitas Syah kuala, Darussalam, Banda Aceh, Vol 4, No 3.

[4] Suhartatik, Nanik, dkk. 2013. Stabilitas Antosianin Beras Ketan ( Oryza sativa var. glutinosa) Hitam Selama Proses Pemanasan dan Penyimpanan. Agritech. Surakarta. Vol 33 No.4.

[5] Hendry, G.A.F dan J.D Houghton. 1996. Natural food Colours. Blackie Academic. London.

[6] Garcia-Palazon, A.2004. The Effects of High Hydrostatic Pressure on $\beta$ glucosidase, Peroxidase and Polyphenoloxidase in Red Raspberry (Rubus idaeus) and Strawberry (Fragaria ananassa), Food Chemistry, 88:7-1.

[7] Hidayah, T. 2013. Uji Stabilitas Pigmen dan Antioksidan Hasil Ekstraksi Zat Warna Alami dari Kulit Buah Naga (Hylocereus udantus). Universitas Negeri Semarang. Semarang. 